\title{
Research of Pipeline Pressure Based on the Reliability
}

\section{Theory}

\author{
Lihang Wang and Pingping Sun \\ School of Petroleum Engineering, Yangtze University, Wuhan 430100, China
}

Received: March 17, 2016 / Accepted: March 24, 2016 / Published: May 31, 2016.

\begin{abstract}
The former gas pipeline operating pressure transmission determined mostly according to the determined formula into the corresponding pipeline parameters are obtained, and the parameters of the actual pipeline due to many reasons, such as measurement error, production batch, etc., is not a fixed value. This paper on pipeline integrity established limit state equation, using Monte Carlo method to calculate the gas pipeline in different pressures of reliability, according to the API (American Petroleum Institute) 579 recommended target reliability to determine the operating pressure of the different regions, and design coefficient method, the calculated results are compared, results of calculation reliability is more reasonable and improve the delivery pressure of the area, the pipeline safety management provides the basis.
\end{abstract}

Key words: Reliability theory, Monte-Carlo method, limit state equation, operating pressure.

\section{Preface}

According to the latest statistics, global in the total number of existing oil and gas pipeline is about 3,500, crude oil transportation pipeline total length of about $33 \times 10^{4} \mathrm{~km}$, refined oil transportation pipeline total length of about $26 \times 10^{4} \mathrm{~km}$, natural gas dry conveying pipeline total length of about $124 \times 10^{4} \mathrm{~km}$. Because of environmental protection, high efficiency, convenient and relatively cheap, and other advantages, will be more rapid development [1].

For known parameters of the pipeline, in the past are through the determination of the method, the basic parameters of the pipeline into the formula to obtain the limit of the operating pressure, and then multiplied by the design factor to get the actual safe operating pressure [2]. However, due to the pipeline production batch and measurement error, in the actual production, the size of the pipe, the performance of the material is not a fixed value or there is a certain range of fluctuations. Therefore, according to the reliability

Corresponding author: Lihang Wang, master's degree, research fields: reliability and safety analysis of oil and gas pipeline. theory, to calculate the operating pressure of the pipeline is more reasonable, and can improve the transmission pressure and pipeline transport efficiency [3].

In this paper, the limit state equation of X70 and X80 pipeline used in west east gas transmission line is established, and the reliability of the pipeline is analyzed by Monte-Carlo method. According to the target reliability provided by API 579, the limit operation pressure of two kinds of pipes is obtained, and the feasibility of improving the gas pressure is obtained by comparing with the traditional method.

\section{Calculation Method Based on Reliability}

\subsection{Limit State Equation}

The random variables that affect the reliability of pipeline: $x_{1}, x_{2}, \ldots, x_{n}$, then the function is:

$$
Z=\left(x_{1}, x_{2}, \ldots, x_{n}\right)
$$

When $Z>0$, the pipeline is in a safe state; $Z=0$, the pipeline is in the limit state; $Z<0$, the pipeline is the failure state. The limit state equation involved in the pipeline is numerous, and the limit state equation of Ref. [4] is adopted in the literature: 


$$
g=2 \sigma_{y} t-p D
$$

In this function, $\sigma_{y}$ is the yield strength of the pipeline, MPa; $t$ for the pipe wall thickness, $\mathrm{mm}$; $D$ for the pipe diameter, $\mathrm{mm} ; P$ for the operating pressure, MPa.

The purpose of introducing the reliability theory is to deal with the uncertainty of these evaluation parameters, and to improve the accuracy of the evaluation results [5]. From Eq. (2), it can be seen that, the uncertainty of the bearing capacity of the pipeline is mainly due to the deviation of the basic size of the pipe, and the deviation of the yield stress caused by the pipe material.

\subsection{Monte-Carlo Method}

Monte-Carlo method, that is the computer stochastic simulation method, is based on mathematical statistics as the basis of a "random number" method of calculation. The Monte-Carlo method is used to calculate the operating pressure of the pipeline. When the statistical distribution of the random variables is known, the safe state is the condition $Y=Z\left(x_{1}, x_{2}, \ldots\right.$, $\left.x_{n}\right)>0$. The Monte-Carlo method is used to generate a set of pipeline parameters which meet the distribution of random variables $x_{1}, x_{2}, \ldots, x_{n}$, and then to determine whether the random number $Y$ is greater than 0 in the limit state function of the obtained samples. According to this method, the calculation of $N$ times, if $Y / M$ in the presence of $Y / N$ is greater than 0 , when the $N$ tends to infinity, by the large number theorem shows that, the reliability of the pipeline $M / N$.

Monte-Carlo method is applicable to a wide range, as long as the correct model is established, the number of simulation is enough, the results obtained are credible. Other methods are mostly related to the Taylor expansion, the accuracy will be affected, so the use of Monte-Carlo method can effectively avoid these problems. Since the calculation requires a large number of values, Matlab software will be used to complete the calculation.

\section{Determination of Target Reliability}

At present, there are two methods for reliability analysis of pipelines, one is the calculation method based on the reliability theory, and the other is based on the historical data prediction method. According to the method of calculating the theory of standard API (American Petroleum Institute) 579 for one of our region as the low risk area, pipeline target reliability level of 0.99; area of second kind as the risk area, pipeline target reliability is 0.999 ; China's three, four areas for high risk area, the pipeline can be reliability is 0.99999 [6-8].

According to the results calculated by the Monte-Carlo method, the operation pressure of pipeline transportation can be obtained by the standard of the target reliability.

\section{Pipeline Operating Pressure Determination}

At present, the most commonly used two kinds of pipeline for the west east gas pipeline is $\mathrm{X} 70, \mathrm{X} 80$, the basic parameters of the pipeline, such as Table 1 [9]. Since the operation pressure of the west east gas transmission pipeline is still not detailed, we can set the operating pressure to obey the normal distribution, and the coefficient of variation is 0.1 .

In Matlab program by programming the reliability calculation, each pressure point Monte Carlo simulation times for 106 times, 100 times each material of steel pipe. Finally, we get reliable pipeline under different pressure curve, Fig. 1a for X70 pipeline under different confined state reliability curve, Fig. $1 \mathrm{~b}$ for X80 pipeline under different confined state reliability curve.

Can be seen from, Figs. 1a and 1b, one kind of pipelines in the gas pressure is less than $10 \mathrm{MPa}$, the reliability of the pipeline is 1 , with the increasing reliability of the pressure gradually reduced. According to API579, the ultimate gas pressure of two kinds of steel tubes is obtained by the target reliability, and the results are compared with the results obtained by the design coefficient. The results are shown in Table 2. 
Table 1 Basic parameters of piping.

\begin{tabular}{llllllll}
\hline $\begin{array}{l}\text { Steel } \\
\text { grade }\end{array}$ & Specifications & $\begin{array}{l}\text { Mean diameter } \\
\text { of pipe diameter } \\
(\mathrm{mm})\end{array}$ & $\begin{array}{l}\text { Standard } \\
\text { deviation of pipe wall thickness } \\
\text { diameter }(\mathrm{mm})\end{array}$ & $\begin{array}{l}\text { Mean value of } \\
(\mathrm{mm})\end{array}$ & $\begin{array}{l}\text { Standard } \\
\text { deviation of wall yield strength } \\
\text { thickness }(\mathrm{mm})\end{array}$ & $\begin{array}{l}\text { Mean value of } \\
(\mathrm{MPa})\end{array}$ & $\begin{array}{l}\text { Standard } \\
\text { deviation of } \\
\text { yield strength } \\
(\mathrm{MPa})\end{array}$ \\
\hline $\mathrm{X} 70$ & $\phi 1,016 \times 14.6$ & 1,016 & 1.33 & 14.97 & 0.37 & 543 & 18.6 \\
$\mathrm{X} 80$ & $\phi 1,219 \times 18.4$ & 1,219 & 1.33 & 18.86 & 0.46 & 620 & 27.6 \\
\hline
\end{tabular}

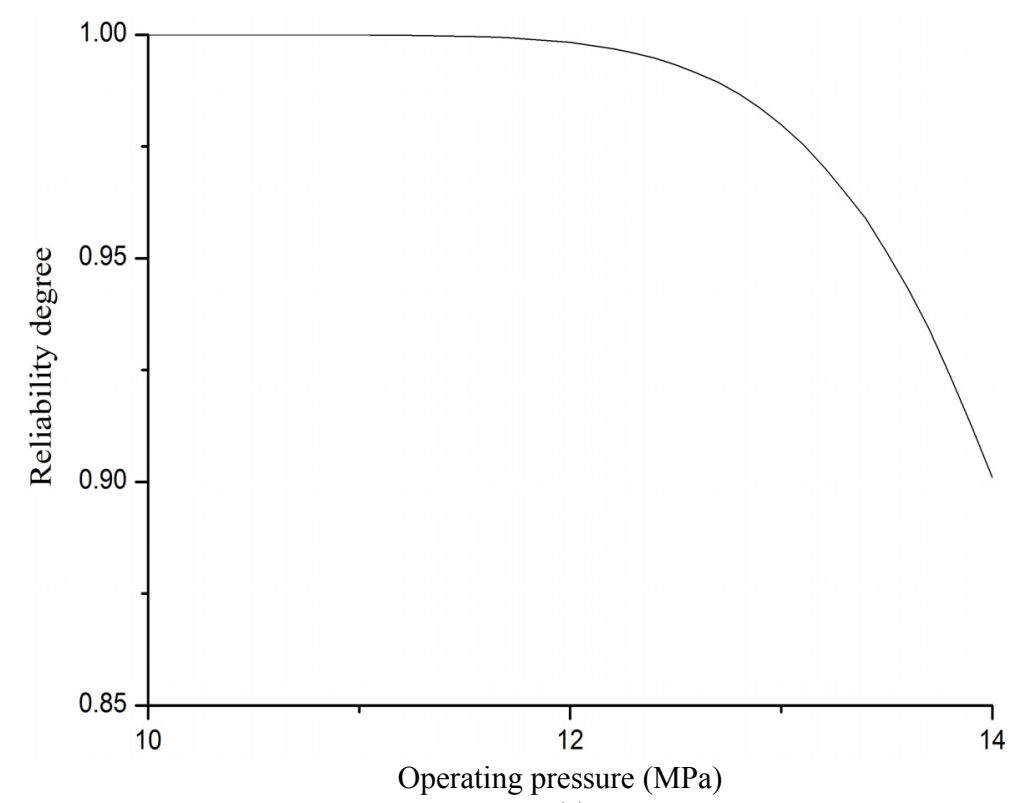

(a)

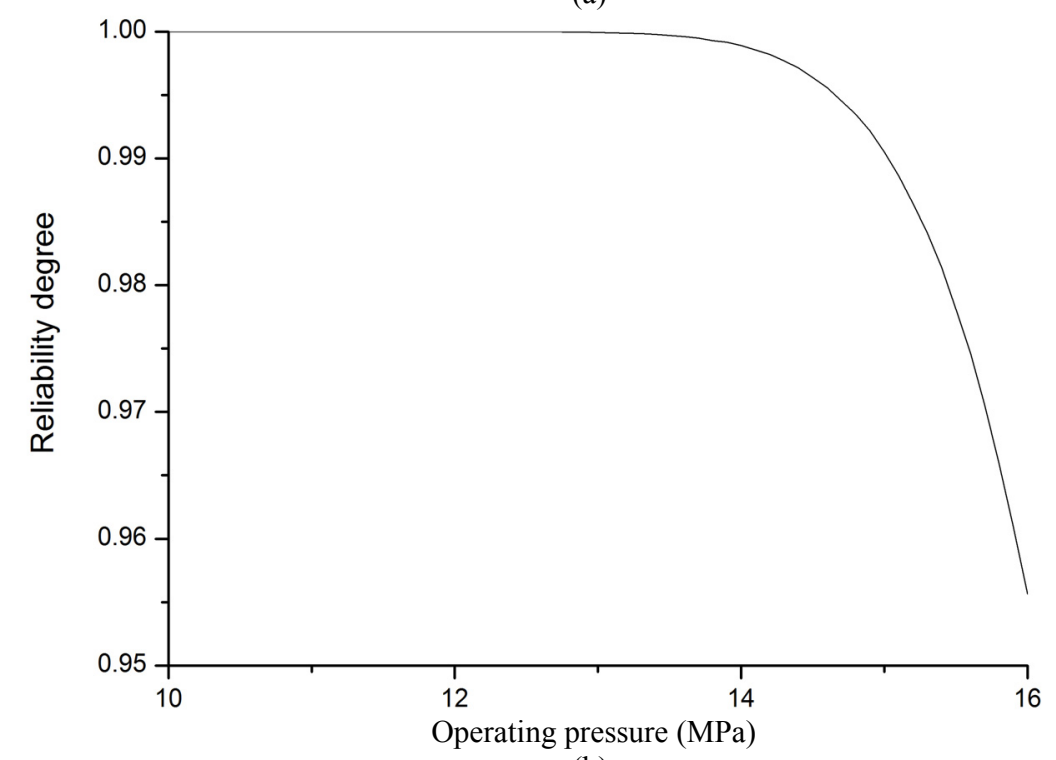

(b)

Fig. 1 Reliability curve of pipeline.

Through the reliability calculation method, two kinds of steel the allowable operating pressure is greater than the design coefficient method to the results, the main reason is the design coefficient method is the material, manufacturing, construction, operation and other aspects of the uncertainty in a unified design coefficient, but for different pipe, these parameters are different, so the design coefficient method to calculate 
Table 2 Operating pressure.

\begin{tabular}{llllll}
\hline & & $\begin{array}{l}\text { The first kind of } \\
\text { regions }\end{array}$ & $\begin{array}{l}\text { The second kind of } \\
\text { regions }\end{array}$ & $\begin{array}{l}\text { The third kind of } \\
\text { regions }\end{array}$ & $\begin{array}{l}\text { The forth kind of } \\
\text { regions }\end{array}$ \\
\cline { 2 - 6 } & & Operating pressure (MPa) & & 6.24 \\
\hline \multirow{2}{*}{ Design coefficient method } & X70 & 11.24 & 9.36 & 7.80 & 7.49 \\
\hline \multirow{2}{*}{ Reliability method } & X80 & 13.48 & 11.23 & 9.35 & 10.68 \\
& $X 70$ & 12.65 & 11.81 & 10.68 & 12.64 \\
\hline
\end{tabular}

the results of more conservative. By analyzing the parameters of the concrete pipe, the reliability method is more ideal and reliable.

\section{Conclusions}

In this paper, the west east gas pipeline $\mathrm{X} 70, \mathrm{X} 80$ line two which were commonly used by reliability method, limit state equation is set up. The reliability of the Monte-Carlo method was used to determine the pipeline, conclusions are as follows:

(1) According to the calculation results, when the operating pressure is less than $10 \mathrm{MPa}$, the reliability of the two kinds of pipelines are 1, with the increasing of pressure, pipeline reliability began to decrease. When the actual pipeline operating pressure less than the target reliability reliability, should take antihypertensive measures to ensure the safe operation of pipeline.

(2) Compared with the design coefficient method, the calculation method based on reliability is more reasonable, but also provides a theoretical basis for the increase of gas pressure.

\section{References}

[1] Hongju, W., Quezhi, Z., and Yanping, Z. 2015. “Overview of Oil and Gas Pipelines in the World." Oil and Gas Storage and Transportation 34 (1): 15-8.

[2] Yunrun, W. 2014. "Natural Gas Pipeline Transportation Increasing Surface Engineering Technology." Oil and Gas Field 33 (5): 11-2.

[3] Caleyo, F., Gonzalez, J. L., and Hallen, J. M. 2002. "A Study of on the Reliability Assessment Methodology for Pipelines with Active Corrosion Defects." International Journal of Pressure Vessels \& Amp, Piping 79 (1): 77-86.

[4] Kai, W., Wenwei, Z., and Jing, G. 2014. "Calculation Method for Reliability of Natural Gas Pipeline." Oil and Gas Storage and Transportation 33 (7): 729-33.

[5] Guangli, Z., Xinwei, Z., and Jinheng, L. 2012. "Based on Different Evaluation Criteria, Containing Corrosion Defects in Tubes Probability Evaluation Method." China Safety Science Journal 22 (9): 57.

[6] British Standards Institution. 1999. BS 7910-1999 Guide on Methods for Assessing the Aceeptability of Flaws in Fusion Welded Structures. London: British Standards Institution.

[7] Milne, I., Ainsworth, R. A., and Dowling, A. R. 1988. "Assessment of the Integrity of Structures Containing Defects: Central Electricity Generating Bord Report." Pressure Vessels and Piping 32 (1-4): 103-4.

[8] British Standards Institution. 1991. BSI PD 6493-1991 Guidelines on Method for Assessment of the Acceptability of Flaws in Fusion Welding Structures. London: British Standards Institution.

[9] Hong, Z., Xiaoting, G., and Liheng, Z. 2011. "Study on Design Coefficient of Oil and Gas Pipeline Based on Reliability." Pipe 34 (4): 58-62. 